\title{
COUGH
}

\section{Idiopathic chronic cough: association with organ specific autoimmune disease and bronchoalveolar lymphocytosis}

\author{
S S Birring, C E Brightling, F A Symon, S G Barlow, A J Wardlaw, I D Pavord
}

Thorax 2003;58:1066-1070

See end of article for authors' affiliations

Correspondence to:

Dr S Birring, Institute for Lung Health, Department of Respiratory Medicine, Glenfield Hospital, Leicester LE3 9QP, UK; sb134@le.ac.uk

Received 12 May 2003 Accepted 30 July 2003
Background: We have recently reported a strong association between organ specific autoimmune disease and idiopathic chronic cough and have suggested that cough may be caused by airway inflammation secondary to aberrant homing of activated lymphocytes to the lung. An immunopathological study was undertaken to test the hypothesis that idiopathic chronic cough is associated with lymphocytic airway inflammation.

Methods: Bronchoscopy, bronchial biopsies, bronchoalveolar lavage (BAL), and peripheral blood and BAL flow cytometry were performed in 19 patients with idiopathic chronic cough, 14 with explained chronic cough, and 11 normal subjects.

Results: Organ specific autoimmune disease or positive autoantibodies were present in eight of the 19 patients with idiopathic cough, in one of the 14 patients with explained cough, and in one of the 11 normal subjects. Median BAL fluid differential lymphyocyte counts were significantly higher in patients with idiopathic cough (10.0\%) than in normal subjects $16.3 \%$, 95\% confidence interval of difference 1.5 to 11.9 , $p=0.01$ ) or patients with explained cough $(5.2 \%, 95 \% \mathrm{Cl}$ of difference 2.0 to $10.4, p=0.001)$. There were no differences in bronchial biopsy $T$ lymphocyte counts between the groups. The mean (SE) proportion of CD3+ peripheral blood mononuclear cells expressing CD4 was significantly higher in normal subjects than in patients with idiopathic cough $(69(3) \%$ v $58(3) \%$, mean difference $11 \%, 95 \% \mathrm{Cl}$ of difference 2 to 20 , $\mathrm{p}<0.02)$ but not than those with explained chronic cough $(63(2) \%)$. There were no differences in BAL T lymphocyte phenotype between groups.

Conclusion: BAL fluid lymphocytosis occurs in some patients with idiopathic chronic cough. The association of idiopathic chronic cough with organ specific autoimmune disease raises the possibility that this might be caused by lymphocyte homing from the primary site of autoimmune inflammation or the result of an autoimmune process in the lung.
C hronic cough is a common presenting symptom in both general practice and respiratory clinics. ${ }^{1}$ The cause of a persistent cough can be identified relatively simply in many cases, with most being due to one or more of asthma, eosinophilic bronchitis, gastro-oesophageal reflux, and rhinitis with postnasal drip. ${ }^{12}$ However in up to $20 \%$ of patients the cough remains unexplained even after extensive investigation and treatment trials. ${ }^{3}$ These patients suffer considerable physical and psychological morbidity. ${ }^{4}$

In a recent case-control study we found that patients with idiopathic chronic cough are predominantly female $(77 \%)$ and are eight times more likely to have an organ specific autoimmune disease, particularly hypothyroidism. ${ }^{5}$ A possible mechanism for the association between idiopathic chronic cough and organ specific autoimmune disease is homing of activated lymphocytes from the primary site of autoimmune inflammation to the lung. Previous small studies have found increased numbers of mononuclear cells in bronchial biopsy specimens ${ }^{67}$ and a $50 \%$ excess of bronchoalveolar lavage (BAL) fluid lymphocytes from patients with idiopathic chronic cough, findings that would be consistent with this mechanism. ${ }^{8}$ A study was undertaken to test the hypothesis that there is lymphocytic bronchoalveolar inflammation and to determine its characteristics in patients with idiopathic chronic cough by evaluating inflammatory cell numbers and phenotype in BAL fluid and bronchial biopsy specimens.

\section{METHODS}

\section{Subjects}

Nineteen patients with idiopathic chronic cough, 14 with explained chronic cough, and 11 normal controls were recruited from Glenfield Hospital outpatient clinics and from healthy volunteers responding to local advertising. Patients with chronic cough were recruited from those attending a specialised cough clinic between January 2000 and December 2001. The clinic receives referrals from primary and secondary care largely confined to a population of 970000 within Leicestershire. Investigations were carried out according to a standardised algorithm and the protocol for investigation and treatment and criteria for accepting diagnosis were as previously described. ${ }^{29}$

We defined idiopathic chronic cough as a cough lasting $>3$ weeks in association with normal clinical examination (including ear/nose/throat), normal chest radiograph and high resolution CT scan, normal lung function tests, negative methacholine inhalation test (provocative concentration $\mathrm{PC}_{20} \mathrm{FEV}_{1}>8 \mathrm{mg} / \mathrm{ml}$ ), normal peak expiratory flow variability, normal sputum differential eosinophil count $(<2 \%)$, and no pathological gastro-oesophageal reflux or evidence of temporal association between cough and gastro-oesophageal reflux on 24 hour oesophageal pH monitoring. Patients had extensive negative treatment trials including trials of inhaled and systemic corticosteroids and trials of antireflux treatment as recommended. ${ }^{9}$ Subjects with explained chronic cough were those in whom there was an identifiable cause for their cough and an improvement in the cough following specific treatment. Normal subjects were asymptomatic and had no evidence of variable airflow obstruction or airway hyperresponsiveness. Six normal subjects and nine patients with explained chronic cough recruited contemporaneously with another study were used for both studies. ${ }^{10}$ All subjects were non-smokers with a past smoking history of less than 10 pack years. None had received corticosteroids or other specific treatment for the condition causing cough for at least 6 weeks before the study. 
Written consent was obtained from all patients and the study protocol was approved by the Leicestershire research ethics committee.

\section{Protocol and clinical measurements}

Subjects attended on three occasions separated by $1-2$ weeks. At the first visit, cough visual analogue score $(0-100 \mathrm{~mm})$, total serum IgE, radioallergosorbent tests to timothy grass, Dermatophagoides pteronyssinus, cat fur and dog dander, a full autoantibody screen (including islet cell, adrenal, parietal, endomysial and thyroid peroxidase autoantibodies), and serum angiotensin converting enzyme (ACE) level were measured. We also measured exhaled nitric oxide, spirometric parameters, and methacholine airway responsiveness. ${ }^{11}{ }^{12}$ Induced sputum was obtained for inflammatory cell differential counts using methods that have been described previously. ${ }^{13}$ None of the subjects had received bronchodilator treatment for at least 12 hours before spirometric and challenge testing. Subjects completed a questionnaire enquiring about the presence of autoimmune disease (hyperthyroidism, hypothyroidism, diabetes, pernicious anaemia, Addison's disease, alopecia, vitiligo, coeliac disease, Crohn's disease, ulcerative colitis, premature menopause, and autoimmune hepatitis). Cough sensitivity was assessed on the second visit with a capsaicin cough challenge test $\mathrm{t}^{14}$ using a dosimeter method standardised to limit inspiratory flow to $0.5 \mathrm{l} / \mathrm{s}$.

At the third visit, subjects underwent bronchoscopy using an Olympus fibreoptic bronchoscope (Olympus Company, Tokyo, Japan) in line with the most recent British Thoracic Society guidelines. ${ }^{15}$ Subjects were pretreated with nebulised $2.5 \mathrm{mg}$ salbutamol 20 minutes before bronchoscopy and were given appropriate sedation as required (midazolam $0-5 \mathrm{mg}$ iv). Lignocaine (1-4\%) was used for local anaesthesia and continuous oxygen was given via nasal cannulae throughout the procedure. A $180 \mathrm{ml}$ BAL of pre-warmed normal saline into the right middle lobe was performed in $60 \mathrm{ml}$ aliquots. Bronchial mucosal biopsy specimens were taken from the right middle and lower lobe carinae. Differential cell counts were obtained from BAL fluid cytospins by two experienced blinded observers. Peripheral blood mononuclear cells (PBMC) from a $20 \mathrm{ml}$ venous blood sample and cells recovered from BAL fluid were analysed using flow cytometry. Mucosal biopsy specimens were immediately transferred into ice cooled acetone containing the protease inhibitors iodoacetamide $(20 \mathrm{mM})$ and PMSF $(2 \mathrm{mM})$ for fixation, stored at $-20^{\circ} \mathrm{C}$ for 24 hours, and then processed into the water soluble resin glycol methacrylate (GMA; Polysciences, Northampton, UK) for embedding. ${ }^{16}$

\section{Flow cytometry}

The PBMC fraction was obtained by centrifugation on Ficoll. For surface receptor expression, PBMC and BAL fluid cells were resuspended in FACS buffer at a concentration of 0.5-1 $\times 10^{6} / \mathrm{ml}$ using a previously described protocol. ${ }^{10}$ Cells were stained with directly conjugated monoclonal antibodies against CD3 ( $\mathrm{T}$ cells), CD4 ( $\mathrm{T}$ helper cells), CD8 ( $\mathrm{T}$ cytotoxic cells), activation markers CD25, CD103 and CD49a, and chemokine receptors CCR3, CCR5, CCR6 and C-X-CR3. Lymphocytes were gated for CD3 expression, then further subdivided by CD4 or CD8 expression and analysed by three colour flow cytometry on a FACScan (Becton Dickinson (BD), Oxford, UK).

\section{Immunohistochemistry}

Two $\mu \mathrm{m}$ sections were cut, floated on $0.2 \%$ ammonia solution in water for 1 minute, and dried at room temperature for 1-4 hours. The following mouse $\operatorname{IgG}_{1}$ monoclonal antibodies were used: CD3 (Dako Ltd, High Wycombe, UK), CD4 (Becton Dickinson, Oxford, UK), CD8 (Dako Ltd.), AAl to mast cell tryptase (Dako Ltd), MBP to eosinophil major basic protein (Bradsure Biologicals, Loughborough, UK), EG2 to the cleaved form of eosinophil cationic protein (ECP) (Pharmacia, Milton Keynes, UK), NE to neutrophil elastase (Dako Ltd), CD45 panleukocyte marker (Dako Ltd), CDl4 to macrophages, (Dako Ltd), CD56 to natural killer (NK) cells (Dako Ltd), 3H4 to interleukin 4 (IL-4; AMS Biotechnology, Abingdon, UK), IL-5 (gift from GlaxoSmithKline, Harlow, UK), interferon gamma (IFN- $\gamma$; R\&D Systems, Abingdon, UK). The technique of immunostaining applied to GMA embedded tissue has been described previously. ${ }^{16}$

Subepithelial mucosa was identified morphologically and the area calculated using a computer analysis system (Scion Image, Maryland, USA). The minimum submucosal area accepted for counting was $0.1 \mathrm{~mm}^{2}$. Nucleated immunostained cells present in coded sections were enumerated in the submucosa and numbers of cells expressed as the number/ $\mathrm{mm}^{2}$ of submucosa by an experienced blinded observer.

\section{Statistical analysis}

Subject characteristics were described using descriptive statistics and expressed as mean (SE). Methacholine $\mathrm{PC}_{20}$ and concentration of capsaicin causing two and five coughs $\left(\mathrm{C}_{2}\right.$ and $\left.\mathrm{C}_{5}, \mu \mathrm{mol} / \mathrm{l}\right)$ were calculated by linear interpolation of the log dose-response curves and described as geometric mean $(\log \mathrm{SE})$. The primary outcome variable-BAL fluid lymphocyte differential cell count-was expressed as median (range). Other differential cell counts and subepithelial cell counts were expressed as medians (range) and flow cytometry data as mean (SE) values. Comparisons across the three groups and between groups were undertaken using the Kruskal-Wallis test and the Mann-Whitney U test, and ANOVA and unpaired $t$ tests were used for non-parametric and parametric data, respectively. $\chi^{2}$ tests were used to make comparisons between groups in the prevalence of autoimmune disease. A p value of $<0.05$ was considered statistically significant.

\section{RESULTS}

The characteristics of the study subjects are shown in table 1. Patients with cough were recruited at random from 236 patients in whom the primary causes of cough were cough variant asthma $(\mathrm{n}=39,17 \%)$, gastro-oesophageal reflux $(n=35,15 \%)$, rhinitis $(n=29,12 \%)$, eosinophilic bronchitis $(\mathrm{n}=17,7 \%)$, idiopathic $(\mathrm{n}=54,23 \%)$, post viral $(\mathrm{n}=17$, $7 \%)$, bronchiectasis $(n=14,6 \%)$, chronic bronchitis $(n=10$, $4 \%)$, enlarged tonsils $(n=8,3 \%)$, pulmonary fibrosis $(n=7$, $3 \%)$, ACE inhibitor cough $(\mathrm{n}=4,2 \%)$, sarcoidosis $(\mathrm{n}=1$, $0.5 \%)$, and bronchial tumour $(n=1,0.5 \%)$. The causes of cough in those with explained chronic cough included in the study were: cough variant asthma $(n=4)$, eosinophilic bronchitis $(n=5)$, gastro-oesophageal reflux $(n=2)$, rhinitis $(\mathrm{n}=2)$, and chronic bronchitis $(\mathrm{n}=1)$. All subjects had a normal serum ACE level. Sixteen of the total population of 54 patients $(30 \%)$ with idiopathic chronic cough had an organ specific autoimmune disease. Six $(32 \%)$ of the 19 patients with idiopathic chronic cough included in the study had clinically overt organ specific autoimmune disease (three hypothyroidism, one hypothyroidism/pernicious anaemia/ vitiligo, one coeliac disease, and one vitiligo) and a further two had positive organ specific autoantibodies (parietal and islet cell) with no clinical evidence of disease. One normal control and one patient with explained cough had positive autoantibodies (islet cell and islet cell/adrenal, respectively); none had clinical evidence of autoimmune disease. The prevalence of organ specific autoimmune disease or positive autoantibody was significantly higher in those with idiopathic chronic cough than in normal subjects or patients with explained chronic cough $(\mathrm{p}=0.01)$. Both cough groups had heightened capsaicin cough reflex sensitivity (table 1). 
Table 1 Characteristics of study subjects

\begin{tabular}{|c|c|c|c|}
\hline & $\begin{array}{l}\text { Normal } \\
(n=11)\end{array}$ & $\begin{array}{l}\text { Idiopathic cough } \\
(\mathrm{n}=19)\end{array}$ & $\begin{array}{l}\text { Explained cough } \\
(n=14)\end{array}$ \\
\hline 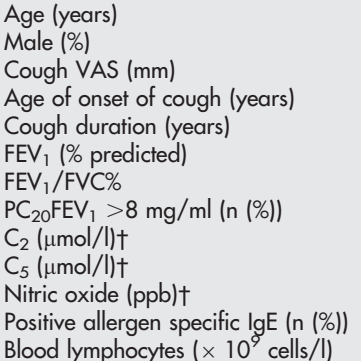 & $\begin{array}{l}52(5) \\
3(27) \\
0 \\
0 \\
111(5) \\
80(2) \\
11(100) \\
47.9(0.2) \\
416.9(0.1) \\
1.8(0.2) \\
1(9) \\
2.1(0.2)\end{array}$ & $\begin{array}{l}54(2) \\
4(21) \\
57(4) \\
47(3) \\
7(3) \\
104(4) \\
80(1) \\
19(100) \\
2.2(0.2)^{*} \\
6.9(0.2)^{*} \\
2.2(0.1) \\
3(16) \\
1.8(0.1)\end{array}$ & $\begin{array}{l}55(4) \\
5(36) \\
51(5) \\
52(4) \\
8(6) \\
101(3) \\
77(2) \\
10(71) \\
2.2(0.2)^{*} \\
11.5(0.3)^{*} \\
5.4(0.1) \\
4(29) \\
2.2(0.1)\end{array}$ \\
\hline \multicolumn{4}{|c|}{$\begin{array}{l}\text { Data expressed as mean (SE) except tgeometric mean }(\log S E) . \\
\text { VAS }=\text { visual analogue score }\left(0-100 \mathrm{~mm}=\text { worst symptom); } C_{2} \text { and } C_{5}=\text { concentration of capsaicin causing two }\right. \\
\text { and five coughs, respectively. } \\
{ }^{*} p<0.001 \text { (ANOVA). }\end{array}$} \\
\hline
\end{tabular}

Sputum and BAL fluid differential inflammatory cell counts are shown in table 2. There were significant differences in the BAL fluid differential and total lymphocyte counts between the three groups $(p=0.002$ and $p=0.003$, respectively; table 2 and fig 1 ). Median BAL fluid differential lymphocyte counts were significantly higher in patients with idiopathic cough $(10.0 \%)$ than in normal subjects $(6.3 \%$; $95 \%$ confidence interval $(\mathrm{CI})$ of difference 1.5 to $11.9, \mathrm{p}=0.01$ ) and in patients with explained cough $(5.2 \%$; 95\% CI of difference 2.0 to $10.4, \mathrm{p}=0.001$; fig 1 ). Median BAL fluid eosinophil counts were significantly higher in the explained cough group than in normal subjects and in those with idiopathic cough (table 2). There were no differences in the other differential cell counts between groups.

There was adequate submucosa with good morphology suitable for counting cells in nine normal subjects, 10 patients with idiopathic cough, and 13 with explained cough. No significant differences were seen in T cell (CD3, CD4 and CD8) subepithelial cell counts in biopsy specimens between the groups (table 3 ). There were significant differences in CD56+ and IFN $\gamma+$ subepithelial cell counts between the three groups $(p=0.03$ and $p=0.047$, respectively, table 3$)$. EG2+, $\mathrm{MBP}+$ and $3 \mathrm{H} 4+(\mathrm{IL}-4)$ cells $/ \mathrm{mm}^{2}$ subepithelium were significantly higher in patients with explained cough than in normal subjects and those with idiopathic cough, but there were no significant differences in other cell counts between the groups (table 3 ). The intraclass correlation coefficients for cell counts between two blinded observers were: BAL lymphocytes 0.90 , bronchial biopsy subepithelial cell counts for extracellular stains 0.97 and 0.86 for intracellular stains.

The mean (SE) proportion of CD3+ PBMC expressing CD4 was significantly higher in normal subjects than in patients with idiopathic cough (69 (3)\% v 58 (3)\%, mean difference $11 \%, 95 \%$ CI of difference 2 to $20, \mathrm{p}<0.02)$ and approached significance when compared with subjects with explained cough $(69(3) \% \vee 63(2) \%$, mean difference $7 \%$, 95\% CI of difference -1 to $15, \mathrm{p}=0.08$ ). The mean (SE) PBMC CD4/ CD8 ratio was significantly higher in normal subjects than in patients with idiopathic cough $(2.5(0.4) \vee 1.6(0.2)$, mean difference $0.9,95 \%$ CI 0.1 to $1.8, \mathrm{p}<0.05$ ) but not those with explained cough $(1.8(0.2), p=0.09)$. There were no significant differences between groups in $\mathrm{CD} 3+$ BAL cells expressing CD4 (mean (SE): normal 58 (5)\%, idiopathic cough 59 (3)\%, explained cough $55(4) \%)$ or CD4/CD8 ratio (normal $1.8(0.5) \%$, idiopathic cough $1.6(0.2) \%$, explained cough 1.5 $(0.2) \%)$. No differences were seen between the groups in the proportion of $\mathrm{CD} 3+\mathrm{CD} 4+$ or $\mathrm{CD} 3+\mathrm{CD} 8+(\mathrm{CD} 3+\mathrm{CD} 4-) \mathrm{PBMC}$ and BAL fluid cells expressing activation or chemokine receptors.

\section{DISCUSSION}

This is the first study to address in detail the immunopathology of the lower airway in patients with idiopathic chronic

Table 2 Sputum and BAL fluid differential cell counts (\%)

\begin{tabular}{|c|c|c|c|}
\hline & Normal & Idiopathic cough & Explained cough \\
\hline \multicolumn{4}{|l|}{ Induced sputum } \\
\hline Lymphocytes & $0.5(0-9.8)$ & $0.7(0-5.8)$ & $0.1(0-1.3)$ \\
\hline Eosinophil & $0.5(0-2.0)$ & $0.2(0-0.8)$ & $3.8(0-68)$ \\
\hline Neutrophil & $56(38-84)$ & $50(15-81)$ & $56(11-88)$ \\
\hline Macrophage & $42(12-51)$ & 47 (17-82) & $27(1-86)$ \\
\hline Epithelial cell & $2.5(0.8-15.1)$ & $1.8(0-19.8)$ & $3.4(0-10.8)$ \\
\hline Squamous contamination & $4(0-15)$ & $8(0-35)$ & $6(0-16)$ \\
\hline Viability & $55(20-81)$ & 65 (23-87) & $52(34-83)$ \\
\hline Total cell count $\times 10^{6} / \mathrm{ml}$ & $1.6(0.3-3.6)$ & $0.9(0.2-3.8)$ & $1.4(0.2-12)$ \\
\hline \multicolumn{4}{|l|}{ BAL fluid } \\
\hline Lymphocytes & $6.3(1.4-14.7)$ & $10.0(1.3-47)^{* * *}$ & $5.2(2.2-28.2)$ \\
\hline Total lymphocyte count $\left(\times 10^{6}\right)$ & $0.5(0-1.9)$ & $0.9(0.2-7.1)^{* *}$ & $0.3(0.1-2.2)$ \\
\hline Eosinophil & $0.3(0-2.5)$ & $0.2(0-1.8)$ & $1.5(0-13)^{*}$ \\
\hline Neutrophil & $9(0-24)$ & $5(0-33)$ & $5(0-19)$ \\
\hline Macrophage & $77(43-91)$ & $78(47-88)$ & $81(38-89)$ \\
\hline Epithelial cell & $7(2-26)$ & $5(1-17)$ & $5(2-33)$ \\
\hline Viability & $71(45-85)$ & $69(19-88)$ & 65 (25-95) \\
\hline Recovery (\%) & $24(8-38)$ & 28 (15-39) & $26(19-40)$ \\
\hline Total cell count $\times 10^{6} / \mathrm{ml}$ & $7.0(0.8-48)$ & $7.5(3.1-22.9)$ & $5.4(4.0-8.5)$ \\
\hline
\end{tabular}




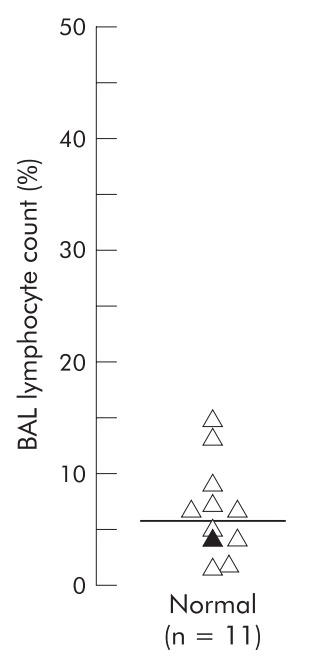

findings is that idiopathic chronic cough is a heterogeneous collection of conditions with distinct pathophysiologies and that BAL fluid lymphocytosis is confined to a subgroup.

The increase in lymphocyte count was seen in BAL fluid but not in induced sputum or bronchial biopsy specimens, suggesting that inflammation might be confined to distal airways and the alveolar compartment. However, the absence of an increase in lymphocyte count in induced sputum cannot necessarily be taken as evidence against involvement of the larger airways, since the proportion of lymphocytes in these samples is low and may not reflect lymphocytic airway inflammation well. ${ }^{11}$ Our findings in bronchial biopsy specimens contrast with other studies where increased numbers of mononuclear cells have been reported in patients with idiopathic chronic cough. ${ }^{67}$ We found reduced numbers of IFN $\gamma+$ and NK cells in idiopathic chronic cough and minor changes in peripheral blood CD4 $\mathrm{T}$ cell phenotypes. The significance of these findings is unclear; they could have arisen by chance because they were not an a priori hypothesis. However, NK cells are a subset of mononuclear cells that play an immunoregulatory role in the prevention of autoimmune diseases, mediating some of their effects through IFN $\gamma$ secretion, ${ }^{20}$ and they have been shown to be both functionally and numerically deficient in individuals at risk of developing organ specific autoimmune disease, ${ }^{21}$ so these findings are potentially relevant to our hypothesis. There is one important caveat to the interpretation of the bronchial biopsy data. Because of technical difficulties, perhaps related to our attempt to do both BAL and bronchial biopsies in patients with a troublesome cough, adequate submucosa for analysis was only available in just over half of the subjects with idiopathic chronic cough so we cannot exclude the possibility that features were missed due to lack of power or bias. Another consideration is that we have studied a wide array of secondary outcome measures, so there is a potential for differences to emerge because of multiple comparisons. As this is the first study to investigate in detail the immunopathology of the lower airway of subjects with idiopathic chronic cough and little is known about the pathogenesis, we feel that a wide ranging descriptive approach is justified. Nevertheless, our findings should be regarded as hypothesis generating rather than definitive, and it is important that further confirmatory studies are performed. Future studies should ideally incorporate larger biopsy specimens and transbronchial biopsy specimens so that better localisation and characterisation of the lower airway inflammatory response is possible.

Bronchoalveolar lymphocytosis is also seen in sarcoidosis, ${ }^{22}$ extrinsic allergic alveolitis, ${ }^{23}$ and pulmonary involvement in rheumatoid arthritis ${ }^{24}$ and Sjogren's disease. ${ }^{25}$ None of the BAL fluid lymphocytosis was not a consistent feature in study and another possible explanation for the inconsistent significant. In contrast, Boulet et $a l^{6}$ found no differences in BAL fluid lymphocyte count in four patients with chronic cough not due to rhinitis or gastro-oesophageal reflux compared with controls. The differences between these studies and ours may relate to power or the precision of diagnosis.

Table 3 Bronchial biopsy subepithelial cell counts per $\mathrm{mm}^{2}$

\begin{tabular}{llll}
\hline & $\begin{array}{l}\text { Normal } \\
(\mathbf{n}=9)\end{array}$ & $\begin{array}{l}\text { Idiopathic cough } \\
(\mathbf{n}=10)\end{array}$ & $\begin{array}{l}\text { Explained cough } \\
(\mathbf{n}=13)\end{array}$ \\
\hline CD3 (T cells) & $38(8-69)$ & $22(6-105)$ & $57(19-125)$ \\
CD4 & $12(0-51)$ & $27(4-119)$ & $33(12-95)$ \\
CD8 & $16(0-33)$ & $9(1-27)$ & $17(0-73)$ \\
IFN & $4.6(0-10.7)$ & $0(0-7.1)^{*}$ & $3.7(0-10.7)$ \\
IL-5 & $5(0-15)$ & $3(0-17)$ & $7(0-21)$ \\
IL-4 & $1.9(0-13.6)$ & $0.3(0-7.4)$ & $5.3(0-11.4)^{*}$ \\
Eosinophils (EG2) & $1(0-12)$ & $2(0-29)$ & $11(0-58)^{*}$ \\
Eosinophils (MBP) & $5(0-19)$ & $7(2-24)$ & $16(3-90)^{*}$ \\
Mast cells & $15(7-50)$ & $19(6-60)$ & $26(15-72)$ \\
Neutrophils & $14(0-50)$ & $24(7-45)$ & $15(4-64)$ \\
Macrophages & $8(0-36)$ & $5(0-18)$ & $11(0-28)$ \\
NK cells (CD56) & $5.3(0-15.6)$ & $0.3(0-4.8)^{*}$ & $2.4(0-13.8)$ \\
Leucocytes (CD45) & $53(6-127)$ & $40(19-90)$ & $56(18-168)$ \\
\hline
\end{tabular}

Data are expressed as median (range). ${ }^{*} \mathrm{p}<0.05$ (Kruskal-Wallis test). 
patients with idiopathic chronic cough had clinical features, radiological findings, or laboratory test results suggesting these diagnoses. BAL fluid lymphocytosis has also been associated with obliterative bronchiolitis in rheumatoid arthritis, Sjogren's disease, lung transplantation, and inflammatory bowel disease. ${ }^{26}{ }^{27}$ It is interesting to speculate that a similar-albeit lower grade-process is operating in our patients, particularly since we have recently reported an association between organ specific autoimmune disease and unexplained fixed airflow obstruction in a population of predominantly older women, many of whom had a long history of dry cough at presentation. ${ }^{28}$

The lungs and many of the organs involved in organ specific autoimmune disorders share common embryological origins as foregut derivatives, and a possible mechanism for the cough and BAL fluid lymphocytosis is homing of activated $\mathrm{T}$ cells into the pulmonary compartment from the primary site of autoimmune inflammation. Similar mechanisms are thought to be responsible for the lymphocytic airway inflammation seen in inflammatory bowel disease, ${ }^{29}$ and it is notable that patients with treated hypothyroidism and inflammatory bowel disease have increased prevalence of respiratory symptoms compared with controls, and that the profile of symptoms reported is remarkably similar. ${ }^{30}$ The concept that aberrant homing of activated lymphocytes occurs in the lung and can result in an isolated cough without physiological and radiological changes is supported by a recent case report of an otherwise unexplained chronic cough associated with BAL fluid lymphocytosis which resolved following treatment of coeliac disease. ${ }^{31}$ The BAL fluid lymphocytosis seen in the current study was not confined to patients with overt organ specific autoimmune disease, perhaps suggesting that the association was not directly related to the presence of lymphocytic inflammation elsewhere. An alternative and intriguing mechanism is that the cough might be due to a hitherto unrecognised autoimmune bronchitis, bronchiolitis, or subtle interstitial process and that the association with other diseases simply reflects the well recognised association between different organ specific autoimmune diseases.

One question is: why was corticosteroid treatment not helpful in our patients? This may be because autoimmune hypothyroidism, pernicious anaemia, insulin dependent diabetes mellitus, and other organ specific autoimmune disorders differ from systemic autoimmune diseases such as systemic lupus erythematosus and rheumatoid arthritis in that they do not respond well to corticosteroids. ${ }^{18}$ Moreover, corticosteroid treatment is disappointing in pulmonary complications of some conditions associated with BAL fluid lymphocytosis such as rheumatoid arthritis and lung transplantation. ${ }^{26}$

In summary, we have found BAL fluid lymphocytosis in some patients with idiopathic chronic cough. These patients were predominantly middle aged women and there was a high prevalence of organ specific autoimmune disease, raising the possibility of a link between autoimmune inflammation, lymphocytic inflammation in the lung and cough. Further studies are required to investigate the mechanism of BAL fluid lymphocytosis and its relation to cough.

\section{ACKNOWLEDGEMENTS}

The authors thank the study participants, D Parker and T Huynh for assistance in the laboratory, and Mrs S McKenna and Mrs B Hargadon for assistance in the clinical characterisation of some of the patients.

\section{Authors' affiliations S S Birring, C E Brightling, F A Symon, S G Barlow, A J Wardlaw, I D Pavord, Institute for Lung Health, Department of Respiratory Medicine, Glenfield Hospital, Leicester, UK}

Supported by a grant from the British Lung Foundation and University Hospitals of Leicester NHS Trust.

SSB is a British Lung Foundation clinical research fellow.

\section{REFERENCES}

1 Irwin RS, Madison JM. The diagnosis and treatment of cough. N Engl J Med 2000;343:1715-21.

2 Brightling CE, Ward R, Goh KL, et al. Eosinophilic bronchitis is an important cause of chronic cough. Am J Respir Crit Care Med 1999;160:406-10.

3 McGarvey LP, Heaney LG, Lawson JT, et al. Evaluation and outcome of patients with chronic non-productive cough using a comprehensive diagnostic protocol. Thorax 1998;53:738-43.

4 Birring SS, Prudon P, Carr AJ, et al. Development of a symptom specific health status measure for patients with chronic cough: Leicester Cough Questionnaire (LCQ). Thorax 2003;58:339-43.

5 Birring SS, Murphy AC, Scullion JE, et al. Idiopathic chronic cough and organ specific autoimmune diseases: a case-control study. Respir Med 2003 (in press).

6 Boulet LP, Milot J, Boutet M, et al. Airway inflammation in nonasthmatic subjects with chronic cough. Am J Respir Crit Care Med 1994;149:482-9.

7 Lee SY, Cho JY, Shim JJ, et al. Airway inflammation as an assessment of chronic nonproductive cough. Chest 2001;120:1114-20.

8 McGarvey LP, Forsythe P, Heaney LG, et al. Bronchoalveolar lavage findings in patients with chronic nonproductive cough. Eur Respir J 1999;13:59-65.

9 Irwin RS, Boulet LP, Cloutier MM, et al. Managing cough as a defense mechanism and as a symptom. A consensus panel report of the American College of Chest Physicians. Chest 1998;114:133-81S.

10 Brightling CE, Symon FA, Birring SS, et al. TH2 cytokine expression in bronchoalveolar lavage fluid T lymphocytes and bronchial submucosa is a feature of asthma and eosinophilic bronchitis. J Allergy Clin Immunol 2002; 110:899-905.

11 Green RH, Brightling CE, McKenna S, et al. Asthma exacerbations and sputum eosinophil counts: a randomised controlled trial. Lancet 2002;360:1715-21.

12 Juniper EF, Cockcroft DW, Hargreave FE. Histamine and methacholine inhalation tests: a laboratory tidal breathing protocol. Lund, Sweden: Astra Daco DB, 1994.

13 Pavord ID, Pizzichini MM, Pizzichini E, et al. The use of induced sputum to investigate airway inflammation. Thorax 1997;52:498-501.

14 Brightling CE, Ward R, Wardlaw AJ, et al. Airway inflammation, airway responsiveness and cough before and after inhaled budesonide in patients with eosinophilic bronchitis. Eur Respir J 2000;15:682-6.

15 British Thoracic Society. British Thoracic Society guidelines on diagnostic flexible bronchoscopy. Thorax 2001;56(Suppl 1):i1-21.

16 Britten KM, Howarth PH, Roche WR. Immunohistochemistry on resin sections: a comparison of resin embedding techniques for small mucosal biopsies. Biotech Histochem 1993;68:271-80.

17 Prudon B, Birring SS, Vara DD, et al. Repeatability of capsaicin cough reflex sensitivity measurement. Thorax 2002;57(Suppl III):iii23.

18 Rose NR, McKay IR. The autoimmune diseases. San Diego: Academic Press, 1998.

19 Mackay IR. Science, medicine, and the future: tolerance and autoimmunity. BMJ 2000;321:93-6.

20 Baxter AG, Smyth MJ. The role of NK cells in autoimmune disease. Autoimmunity 2002;35:1-14.

21 Sharif S, Arreaza GA, Zucker P, et al. Regulatory natural killer T cells protect against spontaneous and recurrent type 1 diabetes. Ann NY Acad Sci 2002:958:77-88.

22 Invi N, Chida K, Suda T, et al. TH1/TH2 and TC1/TC2 profiles in peripheral blood and bronchoalveolar lavage fluid cells in pulmonary sarcoidosis. $J$ Allergy Clin Immunol 2001; 107:337-44.

23 Wahlstrom J, Berlin $M$, Lundgren $R$, et al. Lung and blood T-cell receptor repertoire in extrinsic allergic alveolitis. Eur Respir J 1997; 10:772-9.

24 Gabbay $E$, Tarala R, Will R, et al. Interstitial lung disease in recent onset rheumatoid arthritis. Am J Respir Crit Care Med 1997; 156:528-35.

25 Wallaert B, Prin L, Hatron PY, et al. Lymphocyte subpopulations in bronchoalveolar lavage in Sjogren's syndrome. Evidence for an expansion of cytotoxic/suppressor subset in patients with alveolar neutrophilia. Chest 1987;92:1025-31.

26 Wright JL, Cagle P, Churg A, et al. Diseases of the small airways. Am Rev Respir Dis 1992;146:240-62. 27 Tiroke AH, Bewig B, Haverich A. Bronchoalveolar lavage in lung

28 Birring SS, Brightling CE, Bradding P, et al. Clinical, radiologic, and induced sputum features of chronic obstructive pulmonary disease in nonsmokers: a descriptive study. Am J Respir Crit Care Med 2002;166:1078-83.

29 Wallaert B, Colombel JF, Tonnel AB, et al. Evidence of lymphocyte alveolitis in Crohn's disease. Chest 1985;87:363-7.

30 Birring SS, Morgan AJ, Prudon B, et al. Respiratory symptoms in patients with treated hypothyroidism and inflammatory bowel disease. Thorax 2003:58:533-6.

31 Brightling CE, Symon FA, Birring SS, et al. A case of cough, lymphocytic bronchoalveolitis and coeliac disease with improvement following a gluten free diet. Thorax 2002;57:91-2. 